\title{
Extraction and Characterisation of Cellulose Materials from Sri Lankan Agricultural Waste
}

\author{
Nanayakkara M.P.A. ${ }^{1}$, Pabasara W.G.A. ${ }^{1}$, Samarasekara A.M.P.B. ${ }^{*}$, \\ Amarasinghe D.A.S. ${ }^{1}$, Karunanayake L. ${ }^{2}$ \\ ${ }^{1}$ Department of Materials Science \& Engineering, University of Moratuwa, Sri Lanka \\ ${ }^{2}$ Department of Chemistry, University of Sri Jayewardenepura, Sri Lanka \\ *banduamp@gmail.com
}

\begin{abstract}
Agriculture is a key sector of Sri Lankan economy today. Sri Lanka's main food crop is rice. Rice is cultivated mainly in two seasons in the country. Rice production is the predominant form of agriculture which occupies 0.77 million hectares of the total cultivated area in Sri Lanka. Nevertheless, generation of enormous amounts of agricultural residues such as rice straw during rice production has become inevitable According to the statistics it is revealed that one ton of rice paddy produces $290 \mathrm{~kg}$ of rice straw. Regardless of these large amounts, rice straw is frequently abolished by open field burning by majority of farmers. However, recent researchers have reported that rice straw burning can be lethal towards human health due to the noxious emissions which cause various forms of environmental pollution. Hence, identifying the means of generating value added products by utilisation of rice straw has become a necessity today. Rice straw is a lingo cellulosic biomass which consists of biopolymers of cellulose, hemicellulose and lignin. Cellulose is the mostly abundant organic polymer on earth that can be identified as one of the most demanded advanced materials in engineering applications such as bio composites production. Therefore, developing a method to isolate cellulose from rice straw would be a convenient means of value addition to the agricultural waste. This research work is based on developing an environmentally friendly, efficient method to synthesise cellulose from rice straws of the most frequently cultivated hybrid rice variety (BG352) in Sri Lanka. BG 352 rice variety is cultivated in most of the areas in Sri Lanka today. High purity cellulose was extracted from rice straw by the removal of non-cellulosic materials. This chemical purification process consisted of dewaxing, delignification and hemicellulose and silica removal treatments. FTIR spectroscopy was used to verify the formation of pure cellulose during the extraction process. Further, morphology of extracted cellulose was studied by SEM analysis. It revealed that isolated cellulose was mostly in the form of fibers with diameters ranging from $2-8 \mu \mathrm{m}$. This research showed that BG352 variety averagely has $16.1 \mathrm{wt} . \%$ wax, $38.2 \mathrm{wt} . \%$ lignin, $3.9 \% \mathrm{wt}$. hemicellulose and 12.3 wt.\% silica content. Ultimately, average cellulose yield from rice straws of BG352 variety was observed as $30 \mathrm{wt} \%$. This extraction process can be used to synthesis the cellulose from Sri Lankan agricultural waste to convert it into a value added product.
\end{abstract}

Keywords: Rice straw, Agricultural waste, Cellulose, Lignocellulosic, Biopolymer

Proceedings of the $22^{\text {nd }}$ International Forestry and Environment Symposium 2017 of the Department of Forestry and Environmental Science, University of Sri Jayewardenepura, Sri Lanka 